East African Medical Journal Vol. 81 No. 3 March 2004

PATTERN OF TRANSITIONAL CELL CARCINOMA OF THE URINARY BLADDER AS SEEN AT KENYATTA NATIONAL HOSPITAL, NAIROBI

C. G.Waihenya, MBChB., MMed., (Surg.), District Surgeon, Thika District Hospital, P.O. Box 6117, Thika, Kenya and P.N.Mungai MBChB, MMed., (Surg.).,

Urology, RCS (ENGLAND), Senior Lecturer, Department of Surgery, College of Health Sciences University of Nairobi, P. O. Box 19676, Nairobi, Kenya.

Request for reprints to: Dr. C. G. Waihenya, Thika District Hospital, P.O. Box 6117, Thika, Kenya

\title{
PATTERN OF TRANSITIONAL CELL CARCINOMA OF THE URINARY BLADDER AS SEEN AT KENYATTA NATIONAL HOSPITAL, NAIROBI
}

\author{
C. G. WAIHENYA and P. N. MUNGAI
}

\begin{abstract}
Objective: To highlight the pattern of patients with transitional cell carcinoma of the urinary bladder with regards to age, sex, ethnic origin and histopathological classification. Design: A ten year retrospective study.

Setting: Kenyatta National Hospital, Nairobi, Kenya.

Subjects: Fifty two patients who presented at Kenyatta National Hospital over the ten year period with histologically proven transitional cell carcinoma of the urinary bladder. There were 41 males and 11 females aged 27 to 84 years. The mean age was 57 years. Results: The peak incidence was in the 60-69 years age group. The male to female ratio was 4:1. The regional (provincial) distribution revealed Central and Eastern had $77 \%$, Rift valley had 6\%, Nairobi, North Eastern, Western and Coast provinces had $2 \%$ each. In the ethnic distribution; Kikuyus, Kambas and Merus were $77 \%$ while others were $17.3 \%$. Transitional cell carcinoma was found in $67 \%$ of the patients, $60 \%$ had advanced disease. Twenty nine percent were smokers while $25 \%$ consumed alcohol. The main occupation was farming in $65 \%$. The most Common clinical presentations were haematuria $98 \%$ and lower abdominal pains in $71 \%$. A total of 99,028 patients were admitted to the surgical wards,transitional cell carcinoma patients represented only $0.6 \%$.

Conclusion: Transitional cell carcinoma is a rare disease. At Kenyatta National Hospital it only represented $0.6 \%$ of all surgical admissions during the study period. It accounted for $67 \%$ of all bladder tumours an increase in incidence compared to previous studies. It is common in males more than females, with a peak in the seventh decade. Majority of the patients were from central Kenya. Alcohol, smoking and farming were the most important risk factors. Haematuria was the most important presenting clinical feature. Poor record keeping may have contributed to the low number of patients enrolled into the study. There is need for a thorough prospective study to find out the actual prevalence of bladder tumours.
\end{abstract}

\section{INTRODUCTION}

Urinary bladder cancer represents a significant proportion of urologist's caseload because of its ubiquity and in the superficial disease long natural history. It is more common in men than women $(2.3: 1)$. In men it is the fourth most common cancer after prostate, lung and colorectal tumours(1).

Carcinoma arising from the bladder may be of three cell types; transitional, squamous and adenocarcinoma. Bladder cancer is the most common cancer of the urinary tract and transitional cell carcinoma accounts for more than $90 \%$ of bladder tumours in western countries(2). In areas where Schistosoma haematobium is endemic the proportions are different. Ndaguatha in a review of urinary bladder cancers in Kenyatta National Hospital found $53.3 \%$ were transitional cell, $17.3 \%$ were anaplastic, $13.3 \%$ were squamous cell carcinomas and others were $16.1 \%(3)$.
This tumour features the entire range of aggressiveness from low-grade superficial to high-grade invasive cancers. The incidences are higher in whites than blacks, ratio $2: 1(4,5)$, however the increased risk in whites appears to be limited to patients with noninvasive tumours(6). The observation suggests that some superficial tumours in blacks may go undetected.

The tumour can occur at any age even in children but it is generally a disease of the elderly with the median age of diagnosis being approximately 67 to 70 years. The aetiology of urinary bladder cancer remains unknown, but there are several predisposing factors. These include chemicals, cigarette smoking, radiotherapy and chemotherapy, chronic cystitis and schistosomiasis and bowel interposition.

Increase in understanding of the genetics of the bladder cancer has provided insights into the basis of the clinical behaviour of the tumours(5). The first suspicion of a chemical cause of bladder tumours was 
raised by Rehn in 1894 when he recorded a series of tumours in workers in aniline dye factories(7). Aniline dyes were introduced in the mid-1800s to colour fabrics. Other such chemicals (e.g. 1-naphthylamine, xenylanine and benzidine) have since been identified(8).

There is a strong correlation between incidence of bladder cancer and cigarette smoking, with a four fold higher incidence of the disease in smokers(9-11). The risk correlates with the number of cigarettes smoked, the duration of smoking and the degree of inhalation of the smoke. This risk has been observed in both sexes. Ex-cigarette smokers have a reduced incidence of bladder cancer compared with smokers(12). Other forms of tobacco are associated with only a slight higher risk for bladder cancer $(9,13)$. An estimated one third of bladder cancer patients may be related to cigarette smoking(14).

The specific chemical carcinogen has not been identified but nitrosamines as well as 2- naphthylamine are known to be present. Increased urinary tryptophan metabolites also have been demonstrated in cigarette smokers(15). A significantly higher incidence of bladder cancer has been seen in-patients previously treated with pelvic irradiation or the chemotherapeutic drug cyclophosphamide(5).

Chronic cystitis due to infections and bladder calculi have been associated with increased incidence of urinary bladder cancer. In African patients, schistosomiasis appears to be related to a high incidence of not only squamous cell carcinoma but also other histological types. In a recent study by Groeneveld $e t$ al. schistosomiasis of the bladder was found in $85 \%$ of patients with squamous cell carcinomas, $50 \%$ of those with undifferentiated tumours and adenocarcinoma, in $17 \%$ of those with mixed tumours or sarcomas and in $10 \%$ of the patients with transitional cell carcinoma(16).

The resurgence in the use of bowel in bladder augumentation, and orthotopic replacement of the bladder has led to an increase of reports of patients with bladder cancer arising in the interposed bowel. All patients with interposed bowel in the urogenital system need life long follow-up because of the potentially greater risk of neoplasia caused by increased formation of nitrites and nitroso compounds in the bladder hence the need for regular check cystoscopies.

Molecular genetics have a role to play. It is thought that tumour development and progression is driven by accumulation of multiple genetic alteration by the normal cell. Many phenotypic changes in tumour cell events that are secondary to primary genetic alterations and some of these may have been caused by changes in the environment. The genetics of the bladder carcinogenesis is thought to be multifactorial, involving the action of proto-oncogenes through mutation of gene amplification. Several proto-oncogenes are over-expressed in bladder cancers, these include HRAS
(ERBBI), EGFR (ERBB2), MYC and SRC. Their precise role is yet to be defined.

It is still unclear, however, how these alterations and deletions may be integrated in the development of bladder cancer(17). Pathologically, bladder cancer appears to progress from carcinoma in situ to a fixed mass (T4b) with worsening of prognosis in successive stage of the disease.

Further more carcinoma in situ may represent a parallel rather than a continuous form of the disease.

\section{MATERIALS AND METHODS}

The study was carried out at Kenyatta National Hospital. This was a retrospective study covering a period of ten years from January 1990 to December 1999. Only those patients with histologically confirmed diagnosis of transitional cell carcinoma of the urinary bladder treated at $\mathrm{KNH}$ during the study period were included. The sample size was determined by the study period. The relevant records of the patients with TCC were reviewed after approval of the study proposal by the KNH Research Committee. Data were collected using tally sheets and analysed using statistical computer programme (SPSS).

\section{RESULTS}

During the period of 1990 to $1999,92,028$ patients were admitted to all surgical units of Kenyatta National Hospital. Of these 224 patients were clinically diagnosed to have urinary bladder cancer. Of these 127 (57\%) files were traceable from which 79 had histologically proven bladder cancer. Fifty two, patients of these were transitional cell carcinoma and were enrolled into the study.

The patients were from all parts of the country some seen primarily, others as referrals from provincial, district and mission hospitals. The number of patients recorded from 1990 to 1999 varied from one to ten each year with an average of five patients per anum. The highest number of patients were seen and recorded in the period 1996 to 1998 constituting $69.2 \%$ of all the patients. The 1990 to 1994 figures were low and accounted for $21.1 \%$.

Age/sex: The 52 patients of transitional cell carcinomas were analysed according to the age at presentation. Incidence increased with age. The youngest recorded age was 27 years and the oldest was 84 years. The mean age at presentation was 57.19 years and the median age was 60 years. The range was 57 years. The peak age group was 60 to 69 years accounting for 16 $(30.8 \%)$ of the recorded patients. The other age groups had the following distribution, 20 to 29 years two patients $(3.8 \%), 30$ to 39 years; four patients $(7.7 \%), 40$ to 49 years; 11 patients $(21.2 \%), 50$ to 59 years; eight patients (15.4\%), 70 to 79 years; seven patients (13.5\%), 80 years and above had four patients $(7.7 \%$ ) (Table 1$)$. Gender distribution revealed $78.8 \%$ were males and $21.2 \%$ were females. The male: female ratio was $3.7: 1$. 
Table 1

Patients characteristics

\begin{tabular}{|c|c|c|c|}
\hline Characteristic & No & $\%$ & Cumulative $\%$ \\
\hline \multicolumn{4}{|c|}{ Yearly characteristics in number of patients seen } \\
\hline 1990 & 3 & 5.8 & 5.8 \\
\hline 1991 & 2 & 3.8 & 9.6 \\
\hline 1992 & 4 & 7.7 & 17.3 \\
\hline 1993 & 1 & 1.9 & 19.2 \\
\hline 1994 & 1 & 1.9 & 21.1 \\
\hline 1995 & 7 & 13.5 & 34.6 \\
\hline 1996 & 10 & 19.2 & 53.8 \\
\hline 1997 & 9 & 17.3 & 71.1 \\
\hline 1998 & 10 & 19.2 & 90.3 \\
\hline 1999 & 5 & 9.6 & 100 \\
\hline \multicolumn{4}{|c|}{ Age characteristics (mean age 57.19 years: Range years 27-84) } \\
\hline $20-29$ & 2 & 3.8 & 3.8 \\
\hline $30-39$ & 4 & 7.7 & 11.5 \\
\hline $40-49$ & 11 & 21.2 & 32.7 \\
\hline $50-59$ & 8 & 15.4 & 48.1 \\
\hline $60-69$ & 16 & 30.8 & 78.9 \\
\hline $70-79$ & 7 & 13.5 & 92.9 \\
\hline 80 and Above & 4 & 7.7 & 100 \\
\hline \multirow{2}{*}{\multicolumn{4}{|c|}{$\begin{array}{l}\text { Gender characteristics } \\
\text { Sex }\end{array}$}} \\
\hline & & & \\
\hline Male & 41 & 78.8 & 78.8 \\
\hline Female & 11 & 21.1 & 100 \\
\hline
\end{tabular}

Table 2

Regional and ethnic characteristics

\begin{tabular}{lll}
\hline Characteristic & No. & $\%$ \\
\hline Region & & \\
$\quad$ Nairobi & 1 & 1.9 \\
Central & 24 & 46.2 \\
Eastern & 16 & 30.8 \\
Nyanza & 5 & 9.6 \\
North Eastern & 1 & 1.9 \\
Rift Valley & 3 & 5.8 \\
Western & 1 & 1.9 \\
Coast & 1 & 1.9 \\
Ethnic distribution & & \\
$\quad$ Kikuyu & 27 & 51.9 \\
Kamba & 9 & 17.3 \\
Meru & 4 & 7.7 \\
Luo & 3 & 5.8 \\
Other tribes & 9 & 17.3 \\
\hline Total & 52 & 100 \\
\hline
\end{tabular}


Table 3

Occupation and risk factors characteristics

\begin{tabular}{lll}
\hline Characteristic & No. & $\%$ \\
\hline Occupation & 34 & 65.4 \\
$\quad$ Farmers & 7 & 13.5 \\
$\quad$ Self employed & 5 & 9.6 \\
$\quad$ Salaried employment & 1 & 1.9 \\
$\quad$ Unemployed & 5 & 9.6 \\
$\quad$ Missing data & 52 & 100 \\
Total & & \\
Smoking & 31 & 59.6 \\
$\quad$ Non-smokers & 15 & 28.8 \\
Smokers & 1 & 1.9 \\
Tobacco Snuff & 5 & 9.6 \\
Missing Data & 52 & 100 \\
Total & & \\
Alcohol & 13 & 25.0 \\
$\quad$ Alcohol use & 34 & 65.4 \\
No alcohol & 5 & 9.6 \\
$\quad$ Missing data & 52 & 100 \\
\hline Total & & \\
\hline
\end{tabular}

Table 4

Tumour characteristics and clinical features

\begin{tabular}{lll}
\hline Characteristic & No. & $\%$ \\
\hline Signs/Symptoms & & \\
$\quad$ Haematuria & 51 & 98.1 \\
$\quad$ Lower abdominal pain & 37 & 71.2 \\
$\quad 19$ & 36.5 \\
$\quad$ Pelvic mass & 17 & 31.7 \\
Dysuria & & \\
Histological types & 52 & 67 \\
$\quad$ Transitional cell & 12 & 15 \\
$\quad$ Squamous cell & 6 & 8 \\
$\quad$ Adenocarcinoma & 5 & 6 \\
$\quad$ Anaplastic & 3 & 4 \\
$\quad$ Rhadomyosarcoma & 78 & 100 \\
\hline Total & \multicolumn{2}{|c}{} \\
\hline
\end{tabular}

Regional and ethnic distribution: The provincial distribution was central province, 24 patients (46.2\%), Eastern province, 16 patients $(30.8 \%)$, Nyanza, five patients (9.6\%), Rift Valley three patients (5.8\%), Nairobi, North Eastern, Western and Coast had one patient each (1.9\%). (Table 2). The ethnic distribution was as follows Kikuyu, 27 (51.9\%), Kamba, nine (17.3\%), Meru, four (7.7\%), Luo three $(5.8 \%)$ and other tribes nine (17.3\%) (Table 2).

Risk factors: Smoking was found in $28.8 \%$ of the patients. One patient was using tobacco snuff. There were 13 patients $(25 \%)$ who consumed alcohol, information of five patients was missing from the records (Table 3 ). The amount consumed and durations were not recorded in most of the files.
Clinical presentation: Patients presented with various signs and symptoms, namely haematuria; 51 patients $(98.1 \%)$, low abdominal pains; 37 patients (71.2\%), pelvic mass; 19 patients $(36.5 \%)$, dysuria; 17 patients $(32.7 \%)$. Haematuria was the most common presenting symptom (Table 4).

Histological diagnosis: There were a total of 78 patients seen in the hospital with histologically confirmed urinary bladder cancers for the ten year period. Fifty two $(67 \%)$ of the patients had transitional cell carcinoma, $12(15 \%)$ of the patients had squamous cell carcinomas, six $(8 \%)$ had adenocarcinomas, five $(6 \%)$ had anaplastic and three (4\%) had rhabdomyosarcomas (Table 4). The commonest stage of TCC was muscle invasive in 22 
patients (42.3\%), superficial in 20 patients (38.5\%), metastatic in nine patients $(17.3 \%)$ and carcinoma in situ one patient $(1.9 \%)$. Overall majority of the patients had invasive disease (59.6\%) as compared to superficial (40.4\%). Carcinoma in situ was only recorded at the peak age of 60 to 69 years. Metastatic disease was more common in the age group 30 to 59 years than in older patients.

\section{DISCUSSION}

Transitional cell carcinoma of the urinary bladder is a rare malignancy. In this study covering ten years only 52 patients of histologically proven transitional cell carcinoma patients were seen at Kenyatta National Hospital. This accounts for $67 \%$ of all bladder tumours. Over the same period of time total surgical admissions to the hospital were 99,028. Thus transitional cell carcinoma formed $0.06 \%$ of all surgical admissions in the hospital. The average annual incidence of this condition over the ten year period was 5.2 patients. These figures reveal that there is an increase in the incidence of transitional cell carcinoma from $53 \%$ to $67 \%(3)$.

The highest number of patients were seen and recorded in the period 1995 to 1998 constituting 69.2\% of all the patients. The 1990 to 1993 period figures were low. This may be explained by the poor social economic situation prevailing in the country in this period, where most patients could not afford medical services and opted to stay away or seek medical advice from alternative sources. In the period of 1993 to 1994 there was a national doctors and university lectures strike and this affected the provision of medical services.

In 1995 to 1998 , introduction of cystoscopy as a routine diagnostic tool and transient improvement of the country's economy explains the increase in the number of patients at this time. In the year 1999 the number of patients reduced due to falling socialeconomic status (Table 1). It is possible that there was better record keeping in the year 1996 to 1998.

Peak age incidence of transitional cell carcinoma occurs between 67 to 70 years. In this study, overall peak incidence occurred between 60 to 69 year age group accounting for 16 patients (30.8\%). This compares with the peak incidence of 67 to 70 in the existing literature. The youngest patient was 27 years and the oldest was 84 years with a mean of 57.19 and a median of 60 years. The majority of the patients were between 40 and 69 years $(67.4 \%)$.

In this study $78.8 \%$ of the patients were males and $21.1 \%$ were females giving a male to female ratio of 3.7:1 compared to $2.3: 1$, reported elsewhere $(4,5)$. There was a variation in provincial representation with $46.2 \%$ of patients coming from central province, $30.8 \%$ from Eastern province, 9.6\% from Nyanza, 5.8\% from Rift Valley while Nairobi, North Eastern, Western and Coast provinces had $1.9 \%$ each. The possible reason for this pattern is that $\mathrm{KNH}$ is in close proximity to patients from Central province and therefore easily accessible on logistic grounds. The other possible reason is because Central, Nyanza and Eastern provinces are areas where rice is grown and schistosomiasis is endemic (note that schistosomiasis is responsible for $10 \%$ of TCC)(16). In this study the ethnic distribution were Kikuyu $51.9 \%$, Kamba $17.3 \%$, Meru 7.7\%, Luo $5.8 \%$ and other tribes $17.3 \%$. The reason for this distribution is most likely as stated in the regional distribution.

About $28.8 \%$ were smokers, this account for about a third of all patients with transitional cell carcinoma and is similar to existing literature(14). One of the patients was using tobacco snuff and this is a known risk factor $(9,13)$. None of the patients had a past history of surgery (ureterosigmoidostomy or bladder substitution), chemotherapy or abdominal irradiation which are known risk factors in developing TCC(5).

Farmers constituted $65.4 \%$ of all the patients. It was not specified in the records the type of farming they were engaged in, but it is known that rice farming where schistosomiasis is endemic increases the risk of TCC(16). Haematuria was found in 51 patients $(98.1 \%)$, lower abdominal pain in 37 patients $(71.2 \%)$, pelvic mass in 19 patients $(36.5 \%)$ and dysuria in 17 patients $(32.7 \%)$. Pelvic mass was a sign of advanced disease.

Presentation of transitional cell carcinoma depend on the clinical stage of the disease, presence or absence of metastases, haematuria being the most common presentation(31). Transitional cell carcinoma was the most common urinary bladder malignancy accounting for $67 \%$ of the patients followed by squamous cell $15 \%$, adenocarcinoma $8 \%$, anaplastic $6 \%$ and rhabdomyosarcoma $8 \%$. This revealed an increase in transition cell carcinoma incident compared with figures from other studies(3).

Of the various stages of transitional cell carcinoma, muscle invasive was the most common accounting for 22 patients $(42.3 \%)$ followed by superficial in 20 patients $(38.5 \%)$ metastatic in nine patients $(17.3 \%)$ and carcinoma in situ in one patient (1.9\%). Many early stage tumours could be missed and many patients presented late(6). Muscle invasive histological stage account for the majority of patients of transitional cell carcinoma across the age spectrum.

In conclusion, transitional cell carcinoma is a rare disease in Kenyatta National Hospital. It accounts for $67 \%$ of all bladder tumours, an increase in incidence compared to previous studies. It is common in males more than females, with a peak incidence in the seventh decade. Majority of the patients were from central Kenya. Alcohol, smoking and farming were the most important risk factors. Haematuria was the most important presenting clinical feature. Poor record keeping may have contributed to the low number of patients enrolled into the study. There is need for a thorough prospective study to find out the actual prevalence of bladder tumours. 
Transitional cell carcinoma is a rare disease at Kenyatta National Hospital, common in males than in females, and it is a disease of the elderly. Majority of the patients were from central Kenya. Alcohol, smoking and farming were important risk factors. Haematuria was the most important presenting clinical feature. Poor record keeping may have contributed to the low number of patients enrolled into the study.

\section{ACKNOWLEDGEMENTS}

To the Kenyatta National Hospital Ethical and Research Committe for permission to carry out this study. To Mercy Mugo and the hospital records department staff for assisting in retrieval of the patients records.

\section{REFERENCES}

1. Whelan, P.,and Mayfield M. P. et al. Three year followup of bladder tumours found on screening. Brit. J. Urol. 1993; 72:893-896.

2. Ronsanski, T. A., and Grossman, H.B. Recent developments in the pathophysiology of bladder cancer. Amer. J. Roentgenol. 1994; 163:789-792.

3. Ndaguatha, P. L. W. Clinical presentation of urinary bladder cancers in Kenya. East Afr. Med. J. 1990; 67: 182-190.

4. Annual Cancer Statistics Review 1987. Including Cancer Trends, 1950-1985, NIH publication No. 88-2789. Bethesda, Maryland, U.S Department of Health and Human Services, National Cancer Institute.
5. Morrison, A. S. Advances in the etiology of urothelial cancer. Urol. Clin. North Amer. 1984; 11:557.

6. Schairer, C., Harge, P., Hoover, R. N., et al. Racial differences in bladder cancer risk. A case control study. Amer. J. epidemiol. 1988; 128:1027.

7. Rehn, L. Ueber blasentumoren bei fuchsinarbeitern. Arch. Kind. Chir. 1895; 50:588.

8. Morrison, A. S. and Cole, P. Epidemiology of bladder cancer. Urol. Clin. North Amer. 1976; 3:13.

9. Burch, C.D., Rohan, T. E., et al. Risk of bladder cancer by source and type of tobacco exposure. A case of control study. Int. J. Cancer, 1989; 44:622.

10. Clavel, J., Cordier S., Boccon-Gibod, L., et al. Tobacco and bladder cancer in males: Increased risk of inhalers and smokers of black tobacco. Int. J. Cancer. 1989; 44:605.

11. Morrison, A. S., Buring, J. E., Verhock, W. G, et al. An international study of smoking and bladder cancer. J. Urology, 1984; 131:650.

12. Augustine, A., Hebert, J. R., Kabat, G. C, et al. Bladder cancer in relation to cigarette smoking. Cancer Res. 1988; 48:4405.

13. Harge, P., Hoover, R., and Kantor, A. Bladder cancer risks and pipes, cigars and smokeless tobacco. Cancer. 1985; 55:901.

14. Howe, G. R.., Burch, J.D., Miller et al. Tobacco use, occupation, coffee, various nutrients, and bladder cancer. J. Nat. Cancer Institute. 1980; 64:701.

15. Hoffman, D., Masuda, Y., and Wynder, E. L. Alphanaphthylamine in cigarette smoke. Nature, 1969; 221:254.

16. Groenveld., A.E., Marszalek, W.W., and Heyns, C.F.; Bladder cancer in various population groups in the greater Durban area of Kwa Zulu-Natal, south Africa. Brit. J. Urol. 1996; 78:205-208. 